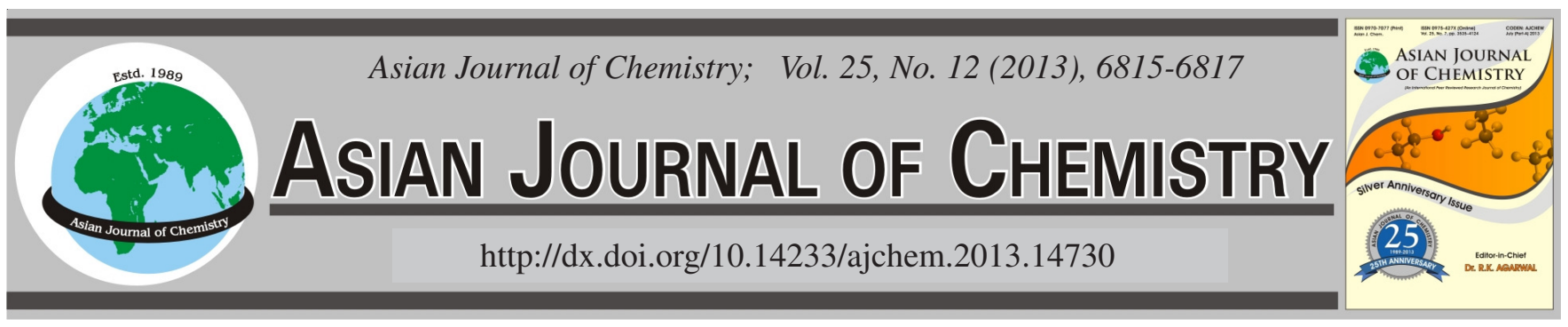

\title{
An Easy Synthesis of Two Steroid-Dihydropyrimidine Derivatives Using Three Components System
}

Lauro Figueroa-Valverde ${ }^{1, *}$, Francisco Díaz-Cedillo², Elodia García-Cervera ${ }^{1}$,
Eduardo Pool-Gómez ${ }^{1}$, Marcela Rosas-Nexticapan ${ }^{3}$ and María López-Ramos ${ }^{1}$

${ }^{1}$ Laboratory of Pharmacochemistry, Faculty of Chemistry-Biological Sciences, University Autonomicof Campeche, Av. Agustín Melgar, Col Buenavista C.P. 24039 Campeche Cam., México

${ }^{2}$ Escuela Nacional de Ciencias Biológicas del Instituto Politécnico Nacional. Prol. Carpio y Plan de Ayala s/n Col. Santo Tomas, D.F. C.P. 11340, México

${ }^{3}$ Facultad de Nutrición, Universidad Veracruzana, Médicos y Odontologos s/n C.P. 91010, Unidad del Bosque Xalapa Veracruz, México

*Corresponding author: Fax: +981 8119800; Ext. 73002; Tel: +981 8119800; Ext. 73006; E-mail: lauro_1999@yahoo.com

(Received: 20 October 2012;

Accepted: 5 June 2013)

AJC-13578

\begin{abstract}
In this study two new steroid-dihydropyrimidine derivatives were synthesized. In the first stage the route involved preparation of 6-(3hydroxy-13-methyl-7,8,9,11,12,13,14,15,16,17-decahydro-6H-cyclopenta[a]-phenanthren-17-yl)-4-phenyl-3,4-dihydro- $1 H$-pyrimidin-2one (4) using estrone, benzaldehyde and urea in the presence of hydrochloric acid. The following stage was achieved by the reaction between pregnenolone, thiourea and benzaldehyde using as catalyst, hydrochloric acid to form the compound 6-[1-(3-hydroxy-10,13dimethyl-2,3,4,7,8,9,10,11,12,13,14,15,16,17-tetradecahydro-1H-cyclopenta[a]phenanthen-17-yl)-ethyl]-4-phenyl-3,4-dihydro-1 $H$-pyrimidine-2-thione (7). The structure of all compounds was confirmed by spectroscopy and spectrometry data. In conclusion, in this study we report an efficient method for synthesis of two steroid-dihydropyrimidine derivatives using three components system. It is important to mention that the method used is highly versatile and the yield is good.
\end{abstract}

Key Words: Steroid, Dihydropyrimidine, Benzaldehyde, Thiourea.

\section{INTRODUCTION}

Combinatorial chemistry is a powerful tool for development of new drugs. In this context, over the past decade, several dihydropyrimidine-derivatives weresynthesized with a wide spectrum of biological actions ${ }^{1,2}$, as antibacterials ${ }^{3,4}$, antivirals $^{5}$ as well as antitumor agents. There are several reports of multi-component reactions for synthesis of dihydropyrimidines. The works reported by Hantzsch ${ }^{6}$ described preparation of 1,4-dihydropyridine using three components system (acetoacetic ester, benzaldehyde and ammonia or ammonium salts) in ethanol. Other reports made by Bignelli ${ }^{7}$ showed the synthesis of dihydropyrimidines derivatives using ethyl acetoacetate, benzaldheyde and urea. Recently the dihydropyrimidin-2(1H)-one was synthesized using the three component system (urea/thiourea, ethylacetoacetate/acetyl acetone) in presence of phosphorus pentoxide ${ }^{8}$. Another works showed the synthesis of 3,4-dihydropyrimidin2-(1H)-ones under solvent-free conditions using ruthenium(III) chloride-catalyzed ${ }^{9}$. In addition, Kappe and coworkers ${ }^{10}$ showed a highly versatile solid-phase synthesis of biofunctional 4-aryl-3,4-dihydropyrimidines using resin-bound isothiourea building blocks and multidirectional resin cleavage. In addition,
Shirini and coworkers ${ }^{11}$ display that $\mathrm{Fe}\left(\mathrm{HSO}_{4}\right)_{3}$ as an efficient catalyst for the preparation of 3,4-dihydropyrimidin-2(1H)ones using the three component system ( $\beta$-keto ester, benzaldheyde and thiourea). Another studies made by Salehia and coworkers ${ }^{12}$ showed the synthesis of dihydropyrimidinones using aldheyde-derivatives, dicarbonyl compounds and urea orthiourea in presence of diammonium hydrogen phosphate. All these experimental data show several protocols for synthesis of dihydropyrimidine-derivatives, nevertheless, the use of expansive reagents requires of specialconditions. In this work our initial design included an easy synthesis of two steroiddihydropyrimidine derivatives using the three components system (pregnenolone or estrone, benzaldehyde and urea or thiourea) in presence of hydrochloric acid.

\section{EXPERIMENTAL}

The compounds evaluated in this study were purchased from Sigma-Aldrich Co., Ltd. The melting points for the different compounds were determined on an Electrothermal (900 model). Infrared spectra were recorded using $\mathrm{KBr}$ pellets on a Perkin Elmer Lambda 40 spectrometer. ${ }^{1} \mathrm{H}$ and ${ }^{13} \mathrm{C}$ NMR spectra were recorded on a Varian VXR-300/5 FT NMR spectrometer at 300 and $75.4 \mathrm{MHz}$ in $\mathrm{CDCl}_{3} /$ acetone- $d_{6}$ using TMS 
as internal standard. EIMS spectra were obtained with a Finnigan Trace GCPolaris Q. spectrometer. Elementary analysis data were acquired from a Perkin Elmer Ser. II CHNS/ 02400 elemental analyzer.

6-(3-Hydroxy-13-methyl-7,8,9,11,12,13,14,15,16,17decahydro-6H-cyclopenta[a]-phenanthren-17-yl)-4-phenyl3,4-dihydro-1H-pyrimidin-2-one (4) (Fig. 1): A solution of estrone $(100 \mathrm{mg}, 0.37 \mathrm{mmol})$, benzaldehyde $(51 \mu \mathrm{L}, 0.50$ $\mathrm{mmol}$ ) and urea (50 mg, $0.83 \mathrm{mmol})$ in $10 \mathrm{~mL}$ of ethanol was stirring for $10 \mathrm{~min}$. After $0.5 \mathrm{~mL}$ of hydrochloric acid was added, the mixture was stirring for $72 \mathrm{~h}$ to room temperature. The reaction mixture was evaporated to a smaller volume. After the mixture was diluted with water and extracted with chloroform. The organic phase was evaporated to dryness under reduced pressure, the residue was purified by crystallization from methanol:water (3:1), yielding $75 \%$ of product, m.p. 160$162{ }^{\circ} \mathrm{C}$; IR (KBr, $\left.v_{\max }, \mathrm{cm}^{-1}\right): 3450,3330,1720 ;{ }^{1} \mathrm{H}$ NMR (300 $\mathrm{MHz}, \mathrm{CDCl}_{3} /$ acetone- $\left.d_{6}\right){ }^{1} \mathrm{H} \mathrm{NMR}\left(300 \mathrm{MHz}, \mathrm{CDCl}_{3} /\right.$ acetone$\left.d_{6}\right) \delta_{\mathrm{H}}: 0.73\left(\mathrm{~s}, 3 \mathrm{H}, \mathrm{C} 18-\mathrm{CH}_{3}\right), 1.60-2.06(\mathrm{~m}, 8 \mathrm{H}), 2.28-2.56$ $(\mathrm{m}, 3 \mathrm{H}), 3.22(\mathrm{~m}, 1 \mathrm{H}), 4.56(\mathrm{~d}, 1 \mathrm{H}, J=5.0 \mathrm{~Hz}), 5.07(\mathrm{~d}, J=$ $5.0 \mathrm{~Hz}), 5.86(\mathrm{~d}, 1 \mathrm{H}, J=9.65 \mathrm{~Hz}), 6.30(\mathrm{~d}, 1 \mathrm{H}, J=9.65 \mathrm{~Hz})$, $6.47(\mathrm{~s}, 1 \mathrm{H}), 6.58(\mathrm{~d}, 1 \mathrm{H}, J=2.70), 6.65(\mathrm{~d}, 1 \mathrm{H}, J=2.70 \mathrm{~Hz})$, 7.02(d, 1H, $J=8.0), 7.18$ (m, $2 \mathrm{H}), 7.38(\mathrm{~m}, 2 \mathrm{H}), 7.50(\mathrm{~m}$, $1 \mathrm{H}), 8.02$ (s, 1H), 9.62 (broad) ppm. ${ }^{13} \mathrm{C} \mathrm{NMR}\left(75.4 \mathrm{~Hz}, \mathrm{CDCl}_{3} /\right.$ acetone- $\left.d_{6}\right) \delta_{\mathrm{C}}: 14.23(\mathrm{C}-31), 25.71(\mathrm{C}-21), 27.02(\mathrm{C}-19), 28.01$ (C-22), 38.46 (C-17), 39.22(C-20), 43.63 (C-14), 44.58 (C-18), 44.79 (C-15), 49.44 (C-16), 58.37 (C-4), 102.25 (C-5, C-30), 113.22 (C-28), 115.56 (C-27), 124.44 (C-13, C-9), 126.06 (C-26), 126.73 (C-12, C-10), 127.61 (C-11), 127.70 (C-24), 132.31 (C-23), 138.18 (C-25), 140.92 (C-8), 144.23 (C-6), 155.02 (C-29), 155.71 (C-2) ppm. EI-MS m/z $\left(\mathrm{I}_{\text {rel. }} \%\right)$ : $426.06\left(\mathrm{M}^{+}\right), 351.21,313.47,271.43,253.39,213.10$, 173.19, 105.14. Anal. calcd. (\%) for $\mathrm{C}_{28} \mathrm{H}_{30} \mathrm{~N}_{2} \mathrm{O}_{2}$ : C, 78.84; $\mathrm{H}$, 7.09; N, 6.57; O, 7.50. Found (\%): C, 78.80; H, 7.06.<smiles>CC12CCC3c4ccc(O)cc4CCC3C1CCC2=O</smiles>
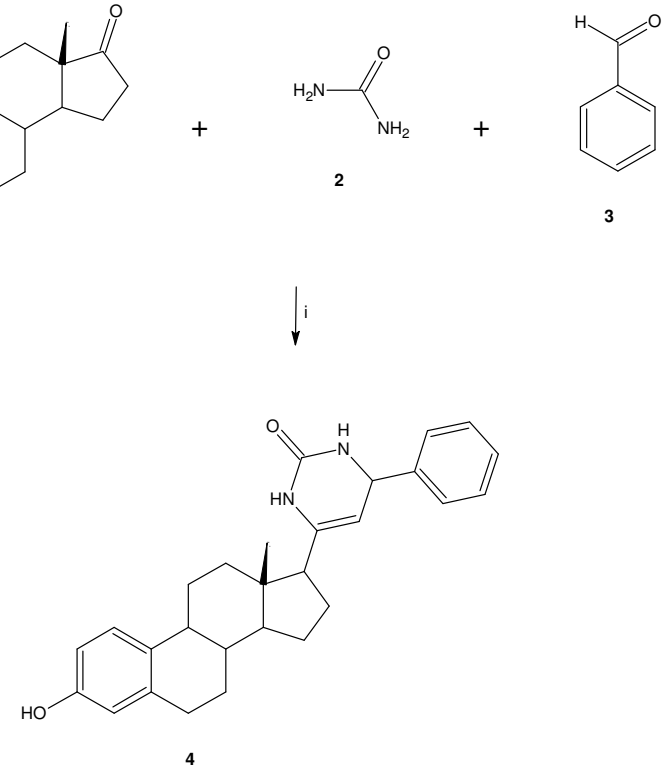

Fig. 1. Synthesis of 6-(3-hydroxy-13-methyl-7,8,9,11,12,13,14,15,16,17decahydro- $6 H$-cyclopenta[a]-phenanthren-17-yl)-4-phenyl-3,4dihydro-1 $H$-pyrimidin-2-one (4). Reaction between estrone (1), urea (2) and benzaldehyde (3) to form 4. i = hydrochloric acid/ethanol/
6-[1 - (3-Hydroxy - 10,13-dimethyl-2,3,4,7,8,9,10, $11,12,13,14,15,16,17$-tetradecahydro- $1 H$-cyclopenta[a]phenanthen-17-yl)-ethyl]-4-phenyl-3,4-dihydro- $1 H$ pyrimidine-2-thione (7) (Fig. 2): A solution of pregnenolone (100 mg, $0.32 \mathrm{mmol})$, benzaldehyde $(51 \mu \mathrm{L}, 0.50 \mathrm{mmol})$ and thiourea $(50 \mathrm{mg}, 0.66 \mathrm{mmol})$ in $10 \mathrm{~mL}$ of ethanol was stirring for $10 \mathrm{~min}$. After $0.5 \mathrm{~mL}$ of hydrochloric acid was added, the mixture was stirring for $72 \mathrm{~h}$ to room temperature. The reaction mixture was evaporated to a smaller volume. After the mixture was diluted with water and extracted with chloroform. The organic phase was evaporated to dryness under reduced pressure, the residue was purified by crystallization from methanol:water (3:1), yielding $66 \%$ of product, m.p. $156{ }^{\circ} \mathrm{C}$; IR $\left(\mathrm{KBr}, \nu_{\max }, \mathrm{cm}^{-1}\right): 3452,3322,1650 ;{ }^{1} \mathrm{H}$ NMR (300 $\left.\mathrm{MHz}, \mathrm{CDCl}_{3}\right) \delta_{\mathrm{H}}: 0.72(\mathrm{~S}, 3 \mathrm{H}), 0.91(\mathrm{~m}, 1 \mathrm{H}), 0.93(\mathrm{~s}, 3 \mathrm{H})$, $1.01(\mathrm{~d}, 3 \mathrm{H}, J=7.0), 1.05-1.92(\mathrm{~m}, 17 \mathrm{H}), 2.08(\mathrm{~m}, 1 \mathrm{H}), 2.28$ $(\mathrm{m}, 2 \mathrm{H}), 3.54(\mathrm{~m}, 1 \mathrm{H}), 4.76(\mathrm{~d}, 1 \mathrm{H}, J=5.0), 5.14(\mathrm{~d}, 1 \mathrm{H}, J=$ 5.0), 5.33 (m, 1H), 6.77 (broad, 3H)7.22-7.50 (m, 5H) ppm. ${ }^{13} \mathrm{C} \mathrm{NMR}\left(75.4 \mathrm{~Hz}, \mathrm{CDCl}_{3} /\right.$ acetone- $\left.d_{6}\right) \delta_{\mathrm{C}}: 12.25(\mathrm{C}-33), 16.59$ (C-32), 19.34 (C-34), 20.91 (C-20), 24.05 (C-23), 29.42 (C22), 31.71 (C-29), 31.75 (C-24), 31.84 (C-18), 36.47 (C-28), 37.43 (C-27), 38.41 (C-16), 39.50 (C-21), 40.39 (C-14), 42.27 (C-31), 50.16 (C-19), 54.19 (C-15), 56.65 (C-17), 63.24 (C4), 71.55 (C-30), 108.22 (C-5), 121.33 (C-25), 127.54 (C11), 127.89 (C-13,C-9), 128.65 (C-12, C-10), 140.75 (C-26), 145.83 (C-8), 151.20 (C-6), 177.82 (C-2) ppm. EI-MS m/z ( $\left.\mathrm{I}_{\text {rel. }} \%\right): 489.97\left(\mathrm{M}^{+}, 7\right), 217.18,(100), 174.24$ (60), 105.17 (45), 78.05 (58). Calcd. (\%) for $\mathrm{C}_{31} \mathrm{H}_{42} \mathrm{~N}_{2} \mathrm{OS}$ : C, 75.87; H, $8.63 ; \mathrm{N}, 5.71 ; \mathrm{S}, 6.53$. Found (\%): C, 75.85; H, 8.64.
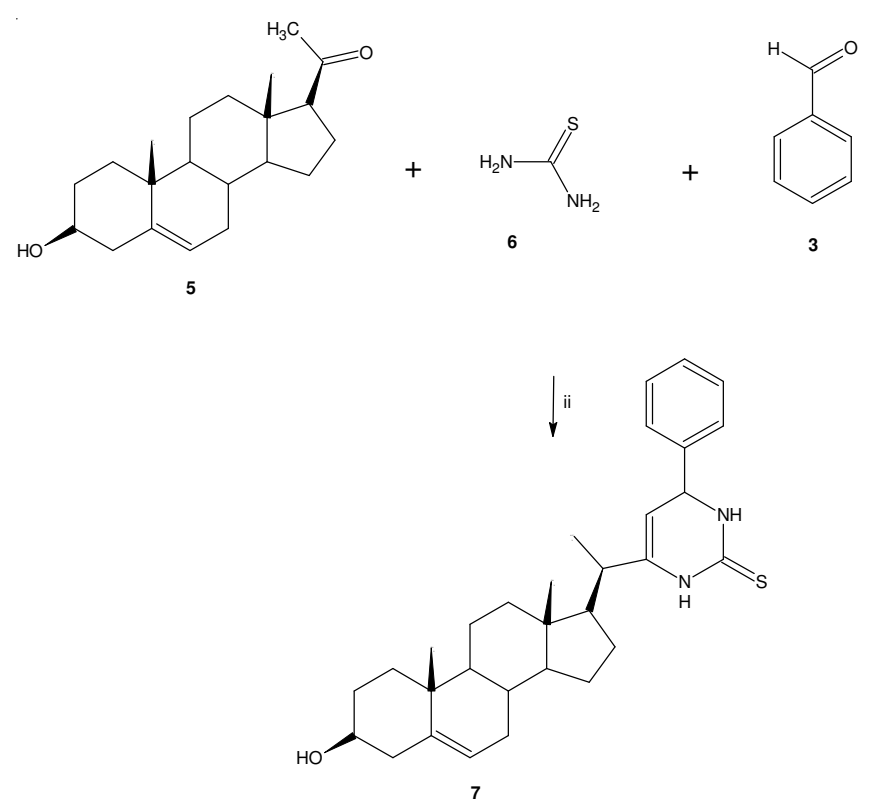

Fig. 2. Synthesis of 6-[1-(3-hydroxy-10,13-dimethyl-2,3,4,7,8,9,10,11,12, $13,14,15,16,17$-tetradecahydro- $1 H$-cyclopenta[a]phenanthen-17yl)-ethyl]-4-phenyl-3,4-dihy-dro-1H-pyrimidine-2-thione (7). Reaction between pregnenolone (1), thiourea (6) and benzaldehyde (3) to form 7. i = hydrochloric acid/ethanol/rt

\section{RESULTS AND DISCUSSION}

In this study two steroid-dihydropyrimidine derivatives were synthesized using the three component system. It is 
important to mention that many procedures for the formation of dihydropyrimidine derivatives are known in the literature. The most widely practiced method employs boric acid ${ }^{13}$, silica sulphuric acid ${ }^{14}$, poly(4-vinylpyridinecodivynylbenzene)$\mathrm{Cu}(\mathrm{II})$ complex ${ }^{15}, \mathrm{H}_{2} \mathrm{SO}_{4}{ }^{16}$, silica triflate ${ }^{17}$ and phosphorus pentoxide ${ }^{18}$. Nevertheless, despite its wide scope, the former protocols suffer from several drawbacks. Some reagents have a limited stability and its preparation can be dangerous. Therefore, in this study in the first stage, estrone (1) was made reacting with thiourea (2) and benzaldehyde (3) using hydrochloric acid as catalyst to form the compound 4 . The results indicate that the ${ }^{1} \mathrm{H}$ NMR spectrum of $\mathbf{4}$ showed signals at $0.73 \mathrm{ppm}$ for methyl group present in the steroid-rings; at 1.603.22 , 5.07-6.30, 6.58-6.65 and $7.02 \mathrm{ppm}$ for methylenes involved in steroid nucleus; at $6.47 \mathrm{ppm}$ for -NH group (pyrimidine-ring). Finally, spectra display several chemical shifts at 7.70 and $8.02 \mathrm{ppm}$ for -NH groups (pyrimidine-ring); at 7.18-7.50 ppm for phenyl groups; at 9.62 for hydroxyl group.

On the other hand, ${ }^{13} \mathrm{C}$ NMR spectra displays chemical shifts at $14.23 \mathrm{ppm}$ for methyl group present in the steroidrings; at 25.71-49.44, 102.25-115.56, 126.06,127.70-138.18 and $155.02 \mathrm{ppm}$ for steroid nucleus; at 58.37, 102.25 and 144.23 ppm for pyrimidine ring. Finally, a signal at 155.71 ppm for carbon bound to oxygen atom involved on pyrimidinering. Additionally, the mass spectra display a molecular ion of $\mathrm{m} / \mathrm{z} 426.06\left(\mathrm{M}^{+}, 17\right)$ which confirm the structure of $\mathbf{4}$.

The second stage was achieved by the reaction between pregnenolone (5), thiourea (6) and benzaldehyde (3) using hydrochloric acid as catalyst to form the compound 7 . The ${ }^{1} \mathrm{H}$ NMR spectrum of 7 showed signals at $0.72,0.93$ and 1.01 ppm for methyl groups; at 0.91and 1.05-1.92, 2.28-3.54 and $5.33 \mathrm{ppm}$ for methylenes involved in steroid nucleus; at 2.10 for methylene bound to pyrimidine-ring; at 4.76-5.14 ppm for protons involved in pyrimidine-ring; at $6.77 \mathrm{ppm}$ for both amino and hydroxyl groups; at 7.22-7.50 ppm for phenyl groups.
On the other hand, ${ }^{13} \mathrm{C}$ NMR spectra displays chemical shifts at 12.25 and 19.34 ppm for methyl groups; at 16.59 , 20.91-39.50, 42.27-56.65, 71.55, 121.33 and 140.75 ppm for steroid nucleus; at $40.39 \mathrm{ppm}$ for carbon bound to pyrimidinering; at 63.24, 108.22 and 151.20 ppm for methylenes involved in the pyrimidine-ring; at 127.54 and $127.89-145.83$ for phenyl group. Finally, a signal at $177.82 \mathrm{ppm}$ for carbon bound to sulphur atom. In addition, the mass spectra display a molecular ion of $\mathrm{m} / \mathrm{z} 489.97\left(\mathrm{M}^{+}, 17\right)$ which confirm the structure of 7 .

\section{REFERENCES}

1. G. Rovnyak, K. Atwal, A. Hedberg, D. Kimball, S. Moreland, J. Gougoutas, B. O’Reilly, J. Schwartz and M. Malley, J. Med. Chem., 35, 3254 (1992).

2. M. Deshmukh, M. Salunkhe, D. Patil and P. Anbhule, Eur. J. Med. Chem., 44, 2651 (2009).

3. R. Mishra, B. Mishra and H. Moorthy, Trends Appl. Sci. Res., 3, 203 (2008).

4. A. Padhy, M. Bardhan and C. Panda, Indian J. Chem., 42B, 910 (2003).

5. S.G. Vishnevskii, V.V. Pirozhenko, N.P. Chentsova, S.V. Antonenko, E.V. Barbasheva, E.V. Grin', M.G. Lyul'chuk, A.E. Sorochinskii, G. Ya. Remennikov, A.I. Puik and V.P. Kukhar', Pharm. Chem. J., 28, 925 (1994).

6. A. Hantzsch, Ber., 14, 1637 (1881).

7. O. Kappe, Eur. J. Med. Chem., 35, 1043 (2000).

8. M. Deshmukh, P. Anbhule, S. Jadhav, A. Mali, S. Jagtap and S. Deshmukh, Indian J. Chem., 46B, 1545 (2007).

9. K. Surya and A. Gibbs, Synthesis, 1748 (2005).

10. C. Kappe, Bioorg. Med. Chem. Lett., 10, 49 (2000).

11. F. Shirinia, M. Zolfigolb and A. Abria, J. Iran. Chem. Soc., 5, 96 (2000).

12. P. Salehia, M. Dabirib, A. Khosropour and P. Roozbehniyab, J. Iran Chem. Soc., 3, 98 (2006).

13. S. Tu, F. Fang, C. Miao, H. Jiang, Y. Feng and D. Shi, Tetrahedron Lett., 44, 6153 (2003).

14. P. Salehi, M. Dabiri, M. Zolfigol and N. Fard, Tetrahedron Lett., 44, 2889 (2003).

15. R. Yarapathi, S. Kurva and S. Tammishetti, Catal. Commun., 5, 511 (2004).

16. J. Bussolari and P. McDonnell, J. Org. Chem., 65, 6777 (2000).

17. F. Shirini, K. Marjani and H. Nahzomi, Arkivoc., 51 (2007).

18. R. Crossland and K. Servis, J. Org. Chem., 35, 3195 (1970). 